\title{
O potencial de desenvolvimento do setor alimentício em Naviraí: uma
} análise de fatores locacionais

\section{The development potential of the food sector in Navirai}

El potencial de desarrollo del sector alimentario en Naviraí: un análisis de los factores regionales.

\section{Caroline Achilles Louza}

UFMS/CPNV.

carolinea.louza@gmail.com

Sibelly Resch Professora, Doutora em Administração, UFMS/CPNV, Brasil. sibelly.resch@ufms.br 


\section{RESUMO}

O objetivo desta pesquisa é investigar o potencial de desenvolvimento do setor alimentício a partir da análise de fatores locacionais da região de Naviraí. O estudo tem como questão de pesquisa: quais fatores locacionais favorecem ou restringem o desenvolvimento do setor alimentício na região de Naviraí? A pesquisa caracteriza-se como qualitativa, de natureza exploratória. Os dados foram coletados por meio de pesquisa documental e bibliográfica. Os resultados apontaram que: a região não produz uma grande variedade de matérias-primas para industrialização, porém, já possui indústrias que beneficiam os principais produtos (bovinos, suínos e mandioca). A cidade possui localização estratégica, tendo boa infraestrutura para o transporte rodoviário terrestre, energia e água. Há disponibilidade de mão de obra e os custos são baixos comparativamente a outros municípios. A taxa de educação formal é baixa, porém, o município conta com o sistema $S$ para qualificação do trabalhador. O município e o estado oferecem incentivos fiscais e tributários relevantes para instalação de indústrias. Conclui-se, nessa primeira etapa da pesquisa, que, de modo amplo, os fatores locacionais investigados favorecem a instalação de indústrias de alimentos no município. Acredita-se que é preciso aprofundar a investigação sobre a complementaridade das indústrias, conforme proposto pela teoria marshalliana, identificando o potencial para o surgimento de indústrias subsidiárias próximas e serviços especializados.

PALAVRAS-CHAVE: Desenvolvimento endógeno; Indústria de alimentos; Fatores locacionais; Mato Grosso do Sul.

\section{ABSTRACT}

The objective of this research is to investigate the development potential of the food sector based on the analysis of locational factors of the Naviraí region. The study has as a research question: which locational factors favor or restrict the development of the food sector in the Navirai region? The research is characterized as qualitative, exploratory in nature. Data were collected through documentary and bibliographic research. The results indicate that: the region does not produce a wide variety of raw materials for industrialization, but already has industries that benefit the main products (cattle, pigs and manioc/cassava). The city is strategically located, with good infrastructure for road transportation, energy and water. Labor is available and costs are low compared to other municipalities. The formal education rate is low, however, the municipality counts on the $S$ system for the qualification of the worker. The municipality and state provide tax incentives relevant to the installation of industries. It is concluded, in this first stage of the research, that, broadly, the locational factors investigated favor the establishment of food industries in the municipality. It is believed that further research on the complementarity of industries, as proposed by the Marshallian theory, is needed to identify the potential for the emergence of nearby subsidiary industries and specialized services.

KEY WORDS: Endogenous Development; Food Industry; Locational Factors; Mato Grosso do Sul.

\section{RESUMEN}

El objetivo de esta investigación es investigar el potencial de desarrollo del sector alimentario basándose en el análisis de los factores localizados en la región de Naviraí. El estudio tiene como cuestión de investigación: ¿Qué factores regionales favorecen o restringen el desarrollo del sector alimentario en la región de Naviraí? La investigación se caracteriza por ser cualitativa, de naturaleza exploratoria. Los datos se recopilaron a través de investigaciones documentales y bibliográficas. Los resultados mostraron que: la región no produce una amplia variedad de materias primas para la industrialización, pero ya cuenta con industrias que benefician a los principales productos (bovinos, cerdos e yuca). La ciudad está estratégicamente ubicada, teniendo una buena infraestructura para el transporte por carretera, energía y agua. La mano de obra está disponible y los costos son bajos en comparación con otros municipios. La tasa de educación formal es baja, sin embargo, el municipio confía en el sistema S para la cualificación del trabajador. El municipio y el estado ofrecen incentivos tributarios y tributarios relevantes para la instalación de industrias. Se concluye, en esta primera etapa de la investigación, que, en términos generales, los factores regionales investigados favorecen la instalación de industrias alimentarias en el municipio. Se cree que es necesario profundizar la investigación sobre la complementariedad de las industrias, como lo propuso la teoría Marshalliana, identificando el potencial para la aparición de las industrias subsidiarias cercanas y los servicios especializados.

PALABRAS CLAVE: Desarrollo Endógeno; Industria alimenticia; Factores regionales; Mato Grosso do Sul. 


\section{INTRODUÇÃO}

Os fatores locacionais são determinantes para a decisão de novos investimentos em determinada localidade (SOUZA e MUNIZ, 2010; FIUZA et al., 2012; LUCIANE, CERETTA e ROCHA, 2014; BRENE et al. 2014; STEIN, 2015; FONTANILLAS et al., 2018). A localização deve ser considerada como um fator determinante para a decisão de investimento pelos empreendedores, pois implica na competitividade das empresas (FIUZA et al. 2012; FONTANILLAS et al., 2018). Desse modo, se, por um lado, a localização é importante para que as empresas sejam competitivas, por outro, diferentes fatores impactam na decisão sobre a localização de uma empresa.

No passado, segundo Fiuza et al. (2012), o problema da localização estava relacionado especialmente ao espaço geográfico, considerando que as decisões locacionais eram determinadas pelos custos de transporte, seja para adquirir os insumos, seja para distribuir os produtos. Com isso, as decisões oscilavam entre proximidade com o mercado consumidor e com as fontes de matérias-primas e insumos.

Esses critérios continuam importantes, entretanto, outros fatores devem ser levados em consideração para a decisão locacional. Tendo como base os estudos de Ramos (2000), Rocha, Bezerra e Mesquita (2010), Souza e Muniz (2010), Fiuza et al. (2012), Andrade (2016) entendese que a análise dos fatores locacionais para definição da localização das firmas deve levar em consideração: a) Custo e eficiência dos transportes para matéria-prima e produtos acabados; b) Áreas de mercados, considerando sua localização e sua dimensão, incluindo nessa análise a concorrência; c) Disponibilidade e custos da mão de obra, avaliada em termos de quantidade e qualidade; d) Custo da terra, no caso das plantas industriais, que necessitam de grandes áreas para sua implantação; e) Infraestrutura, especialmente disponibilidade de energia, água e sistemas de comunicação adequados; f) Suprimento de matérias-primas; g) Eliminação de resíduos e questões de legislação ambiental; h) Dispositivos fiscais e financeiros; i) Instituições, mais especificamente, a eficiência do governo; j) Elementos intangíveis, como por exemplo, hábitos de consumo do mercado ou ainda, fatores sociais, como a disponibilidade de escolas, saúde, lazer, entre outros.

O processo de industrialização gera empregos diretos e indiretos, aumentando os níveis de renda em determinadas regiões. Entretanto, o processo de industrialização não ocorre de forma homogênea (STEIN, 2015; DINIZ, 2017; STAMM et al. 2013). Neste sentido, é imprescindível compreender os fatores que interferem nesse processo, visando especialmente minimizar as desigualdades regionais, presentes em todo o território brasileiro (DINIZ, 2017).

Stamm et al. (2013) e Diniz (2017) afirmam que o Brasil tem vivenciado um processo de desconcentração industrial, com crescimento das cidades de médio porte. A despeito dessa desconcentração, os estados de São Paulo, Rio de Janeiro e Minas Gerais contribuem com mais de $50 \%$ do PIB industrial brasileiro, enquanto estados como o Mato Grosso do Sul contribuem com apenas $1,4 \%$ do PIB (CNI, 2015). Ferreira et al. (2017) apontam que o processo de industrialização de Mato Grosso do Sul iniciou na década de 1970, e, portanto, pode ser considerado como um processo recente, conectado ao setor primário em razão da base agropecuária histórica presente no estado. 
Pereira et al. (2017) identificaram que o município de Naviraí, localizado no sul do Mato Grosso do Sul, com população estimada de 52000 habitantes, constitui-se como cidade polo da microrregião de Iguatemi, atualizada pelo IBGE como microrregião Naviraí/Mundo Novo. Ainda de acordo com Pereira et al. (2017), a cidade de Naviraí obteve um crescimento populacional acima da média regional nos últimos anos e possui o maior PIB da região.

Com o crescimento do município e a partir das políticas de expansão do ensino superior no Brasil, instalaram-se na cidade três instituições de ensino superior públicas, Universidade Federal de Mato Grosso do Sul (UFMS), Instituto Federal de Mato Grosso do Sul (IFMS) e Universidade Estadual de Mato Grosso do Sul (UEMS) e polos de educação a distância vinculados às instituições privadas, que oferecem distintos cursos de graduação e pósgraduação. O município, na análise dos mesmos autores, é também o polo industrial da microrregião, concentrando $35 \%$ do PIB industrial regional. Por se caracterizar como uma cidade polo da região, também concentra serviços e instituições públicas.

Apesar do crescimento vivenciado pela cidade nos últimos anos, a desigualdade econômica e social está presente no município. Entende-se que para melhorar o desenvolvimento da região, é imprescindível atrair novos investimentos, desencadeando um processo de desenvolvimento endógeno que considere as vocações do território (AMARAL FILHO, 2001).

A partir do exposto sobre a importância dos fatores locacionais para a decisão de localização de indústrias e do pressuposto de que a cidade possui vocação para o setor de produção de alimentos, o presente estudo tem como questão de pesquisa: Quais fatores locacionais favorecem ou restringem o desenvolvimento do setor alimentício na região de Naviraí?

O objetivo desta pesquisa é investigar o potencial de desenvolvimento do setor alimentício a partir da análise de fatores locacionais da região de Naviraí. Os objetivos específicos são: a) Construir um panorama sobre os fundamentos da teoria da localização industrial; b) Tendo como foco o setor alimentício, analisar os seguintes fatores locacionais na região de Naviraí: mercado-consumidor, matérias-primas, transporte, mão de obra, infraestrutura e incentivos do poder público no âmbito municipal.

\section{MATERIAL E MÉTODOS}

Considerando a natureza da proposta para a pesquisa, podemos classificá-la como qualitativa, de natureza exploratória. A pesquisa qualitativa, segundo Silveira e Córdova (2009, p. 31) "não se preocupa com representatividade numérica, mas, sim, com o aprofundamento da compreensão de um grupo social, de uma organização, etc.". A pesquisa de natureza exploratória tem como objetivo contribuir com mais informações sobre o assunto investigado, facilitando a delimitação do tema da pesquisa. (PRODANOV e FREITAS, 2013, p. 51). A pesquisa documental e as entrevistas realizadas visaram buscar informações que subsidiassem a análise dos seguintes fatores locacionais na região de Naviraí: mercado-consumidor, matérias-primas, transporte, mão de obra, infraestrutura e incentivos do poder público no âmbito municipal.

A primeira etapa consistiu numa pesquisa bibliográfica visando levantar trabalhos que contribuíssem para a construção do embasamento teórico sobre os fundamentos da teoria da localização industrial. 
Num segundo momento, realizou-se uma pesquisa documental, buscando dados e informações que auxiliassem na identificação das principais matérias-primas presentes na região, na estimativa do mercado consumidor, na identificação das principais rodovias da região, que se constituem no principal modal de transporte de matérias-primas e produtos acabados.

$\mathrm{Na}$ terceira etapa da pesquisa, foram realizadas duas entrevistas semiestruturadas. A primeira, com o gerente de desenvolvimento econômico do município de Naviraí, denominado como FK e a segunda, com a responsável pelo Centro de Atendimento ao Trabalhador (CIAT), instituição pública que faz o recrutamento de pessoal para as empresas, denominada como EF. Os atores foram escolhidos em razão dos objetivos propostos para o estudo. As perguntas do roteiro foram desenvolvidas a partir dos fundamentos teóricos e dos objetivos do trabalho.

As entrevistas foram realizadas no mês de julho de 2018, com o consentimento dos sujeitos para gravação e transcrição. Cabe ressaltar que as informações obtidas são de caráter público, de modo que expressam as políticas e programas governamentais desenvolvidos em Naviraí. Para análise das informações coletadas nas entrevistas, utilizou-se a análise de conteúdo, considerando que se trata de uma técnica que trabalha com a materialidade linguística expressa pelos sujeitos (BAUER, 2002).

\section{RESULTADOS E DISCUSSÃO}

\section{Fundamentos teóricos dos fatores locacionais}

A aglomeração de indústrias numa determinada localidade foi estudada pioneiramente por Marshall (1982) a partir da argumentação de que as atividades similares podem gerar vantagens para as empresas, especialmente para as pequenas, chamadas de economias externas marshallianas, que por sua vez ocorreriam em razão: a) da criação de uma infraestrutura específica para o setor, como por exemplo, o surgimento de indústrias subsidiárias próximas e serviços especializados; b) da troca de informações, formando uma rede de pessoas e firmas, gerando acúmulo de competências produtivas e; c) da formação de uma força de trabalho especializada, pelo acúmulo de conhecimento que surge na comunidade.

Complementarmente à visão marshalliana, as teorias clássicas de localização buscam identificar fatores que influenciam e/ou determinam a decisão para a definição de um local para o desenvolvimento de atividades produtivas pelas firmas, tendo como dois expoentes: Von Thünen e Alfred Weber.

Thünen estudou em 1826 a distribuição das atividades agrícolas em torno de centros urbanos em função dos custos de transporte dos produtos. Sua preocupação estava em determinar a maximização da renda do agricultor e a minimização dos custos, considerando sua distância da cidade e os custos de frete. No contexto agrícola, na visão do autor, a proximidade dos centros urbanos leva a atividades mais lucrativas (RAMOS, 2000; DONDA JÚNIOR, 2002; BETARELLI JÚNIOR e SIMÕES, 2011).

Posteriormente (aproximadamente em 1909), o economista alemão Alfred Weber também focou seus estudos na questão do transporte, voltados, porém, para a atividade industrial. 0 
autor visava identificar um ponto de mínimo custo, buscando determinar uma "localização ótima", considerando o custo de transporte da matéria-prima até a fábrica, o qual dependia do peso do produto e da distância a ser percorrida e também dos produtos acabados até o mercado. Além disso, a proximidade e o custo da mão de obra também se apresentam como fator importante para a localização de uma firma (RAMOS, 2000; DONDA JÚNIOR, 2002; BETARELLI JÚNIOR e SIMÕES, 2011).

A teoria da localização foi discutida por outros autores clássicos, como cita Ramos (2000): Palander, Preddöl, Cristaller, Lösch e Isard. Todavia, essas teorias encontram limites em questões metodológicas ou ainda, pela complexidade dos processos concretos e dinâmicos da concentração das atividades econômicas sobre um determinado espaço. Assim, autores como Perroux, Myrdal e Hirschman passaram a "dar maior ênfase aos fatores dinâmicos da aglomeração, na medida em que incorporaram como fator de localização a 'complementaridade' entre firmas e setores, assim como a noção de economia de escala mínima da firma" (AMARAL FILHO, 2001, p. 263).

Amaral Filho (2001, p. 280) explica que as teorias e as políticas de desenvolvimento regional devem abranger a organização econômica associada a organização setorial (principalmente o sistema industrial) e a organização territorial (principalmente o sistema regional), em razão dos "fatores componentes da escala da produção de uma empresa não se encontrarem necessariamente na própria empresa, mas sim fora dela, isto é, em outras empresas cooperadas ou subcontratadas em outras instituições e organizações, e no próprio ambiente territorial". Desse modo, o que diferencia as regiões é o protagonismo dos atores locais, que devem "trabalhar juntos com o objetivo de criar e de recriar fatores locacionais dinamicamente competitivos" (AMARAL FILHO, 2001, p.280).

$\mathrm{O}$ papel ativo dos atores locais é a base para o desenvolvimento endógeno das regiões. $O$ movimento de endogeneização das regiões do interior dos países vem crescendo desde a década de 1980, com um papel mais ativo dos atores de um território diante da organização industrial. O desenvolvimento endógeno pode ser compreendido como um modelo construído "de baixo para cima, ou seja, que parte das potencialidades socioeconômicas originais do local" (AMARAL FILHO, 2001, p. 268), ou seja, das vocações da região para determinadas atividades industriais.

O poder público exerce importante papel para o desenvolvimento regional, por meio de incentivos à instalação de indústrias nas localidades. Conforme destacam Luciane, Ceretta e Rocha (2017, p. 174), “os fatores institucionais são referentes à disponibilidade e acessibilidade a incentivos e ações de instituições públicas municipal, estadual ou federal, como incentivos fiscais, financiamentos, comodato de instalações e máquinas e outros fomentos públicos". O apoio institucional governamental é um fator decisivo para a instalação das indústrias. Na pesquisa que esses autores realizaram, a maioria das indústrias instaladas num APL de alumínio no Paraná recebeu algum tipo de incentivo do poder público. Um benefício comumente utilizado pelos municípios e estados é a isenção de impostos ou taxas. Segundo Almeida (2017), em alguns casos, outros tipos de benefícios podem ser concedidos às empresas, como a doação de terrenos para a instalação da unidade produtiva da fábrica. 
É fundamental conhecer os fatores que influenciarão em futuras decisões a respeito da localização da indústria, e através disso será possível promover politicas públicas que se adequem melhor à realidade, buscando um equilíbrio social e econômico (STEIN, 2015).

\section{Análise dos fatores locacionais para o desenvolvimento do setor alimentício na região de Naviraí/MS}

Um dos fatores relevantes na Teoria da Localização é o custo com transporte, seja para o recebimento de matérias-primas e insumos, seja para a distribuição do produto acabado. Embora atualmente esse fator não seja restritivo em razão da ampliação da infraestrutura, especialmente para o modal rodoviário no Brasil, ele implica na competitividade da empresa.

Assim, o primeiro dado pesquisado foi a produção agrícola do município. No levantamento, identificou-se que além das culturas de soja e milho, tem crescido no município a plantação de mandioca, tendo sido duplicada a produção entre 2014 e 2015 (Tabela 1).

Esse dado é condizente com a expansão da capacidade produtiva de uma, das duas indústrias de processamento de mandioca (fecularias) localizadas no município. Observa-se também que a produção de cana-de-açúcar teve uma queda drástica após o encerramento das atividades da usina de produção de etanol, ocorrida em 2014. Cabe ressaltar que a indústria de etanol foi vendida para um grupo de investidores, com as atividades de produção retomadas em 2016, totalizando 520.215 toneladas de cana-de-açúcar.

Tabela 1: Produtos Agrícolas/Naviraí-MS (2011-2015)

\begin{tabular}{l|ccccc}
\hline \multirow{2}{*}{ Produtos } & \multicolumn{5}{c}{ PRODUÇÃO (toneladas) } \\
\cline { 2 - 6 } & $\mathbf{2 0 1 1}$ & $\mathbf{2 0 1 2}$ & $\mathbf{2 0 1 3}$ & $\mathbf{2 0 1 4}$ & $\mathbf{2 0 1 5}$ \\
\hline Abacaxi & 38 & 100 & 288 & 315 & 40 \\
Algodão Herbáceo & 698 & 544 & - & - & $\ldots$ \\
Amendoim & - & - & - & - & 469 \\
Café & 05 & 05 & 03 & 03 & 03 \\
Cana-de-açúcar & 1.101 .031 & 642.066 & 588.584 & 673.939 & 94.154 \\
Feijão & 197 & 271 & 448 & 657 & 156 \\
Mandioca & 67.650 & 51.984 & 89.440 & 92.200 & 183.000 \\
Melancia & 60 & 240 & - & - & $\ldots$ \\
Milho & 196.656 & 240.078 & 260.460 & 275.080 & 323.420 \\
Soja & 173.163 & 130.013 & 180.000 & 170.911 & 205.660 \\
Sorgo & - & 2.037 & - & - & $\ldots$ \\
Trigo & 332 & - & - & 839 & 2.477 \\
\hline
\end{tabular}

Fonte: SEMADE, 2015.

Além dos produtos agrícolas, o município de Naviraí se destaca pela produção de bovinos (Tabela 2), com a presença de uma multinacional de processamento de bovinos. A análise dos dados demonstra uma queda em número de cabeças no período analisado. Possivelmente, esse número esteja relacionado ao aumento de área destinada à plantação de soja e milho no município. No caso da soja, passou de 49.903 hectares em 2011 para 74.150 hectares em 2015. Em 2018, uma cooperativa com sede em Naviraí realizou um evento sobre a criação de 
peixes, dando um indicativo de que investirá na piscicultura, ampliando a produção de proteína animal do município.

Tabela 2: Principais rebanhos/Naviraí-MS (2010-2014)

\begin{tabular}{lccccc}
\hline \multicolumn{1}{c}{ Especificação } & $\mathbf{2 0 1 0}$ & $\mathbf{2 0 1 1}$ & $\mathbf{2 0 1 2}$ & $\mathbf{2 0 1 3}$ & $\mathbf{2 0 1 4}$ \\
\hline Bovinos & 243.923 & 242.445 & 229.777 & 210.800 & 193.930 \\
Suínos & 18.630 & 18.815 & 17.046 & 11.500 & 11.650 \\
Equinos & 3.530 & 4.050 & 4.167 & 4.770 & 4.685 \\
Ovinos & 4.720 & 4.318 & 5.130 & 4.750 & 4.730 \\
Aves & 69 & 72 & 43 & 43 & 42 \\
\hline
\end{tabular}

Fonte: SEMADE, 2015.

A Tabela 3 apresenta os principais produtos da pecuária. Observa-se que a quantidade de leite produzida é pequena, quando comparada ao número de cabeças do rebanho bovino, possivelmente pelo foco do município estar no processamento de bovinos e não na criação de animais produtores de leite. Em relação aos produtos da pecuária, nota-se queda na quantidade de mel produzido no município, conforme Tabela 3.

Tabela 3: Principais produtos da pecuária/Naviraí-MS (2010-2014)

\begin{tabular}{lccccc}
\hline \multicolumn{1}{c}{ Especificação } & $\mathbf{2 0 1 0}$ & $\mathbf{2 0 1 1}$ & $\mathbf{2 0 1 2}$ & $\mathbf{2 0 1 3}$ & $\mathbf{2 0 1 4}$ \\
\hline Leite (mil litros) & 4.658 & 3.379 & 2.926 & 3.350 & 4.830 \\
Mel de abelhas (kg) & 48.000 & 45.000 & 23.500 & 12.500 & 11.500 \\
Ovos de galinha (mil dúzias) & 416 & 551 & 437 & 444 & 439 \\
\hline
\end{tabular}

Fonte: SEMADE, 2015.

Dados compilados pela SEMADE (2015), apontam que aproximadamente $15 \%$ das indústrias do município de Naviraí concentram sua atividade no setor produtivo de alimentos. A análise dos dados de produção agrícola e agropecuária, aponta para uma tendência de concentração de indústrias de processamento de carnes e de mandioca no município, considerando a importância da proximidade com a matéria-prima como fator de decisão locacional.

Esses dados são coerentes com a perspectiva do poder público municipal de Naviraí. Em entrevista realizada com o gerente de desenvolvimento econômico do município, o mesmo afirma que as principais matérias-primas são o soja, o milho e a mandioca. Em relação à soja, ele explica que uma indústria esmagadora está se instalando no município de Dourados, localizado a 120 quilômetros da Naviraí. FK também lembra que a cooperativa com sede no município pretende diversificar sua produção, iniciando a produção e comercialização de fécula modificada, sagu e tapioca. Além disso, destaca que uma fábrica de ração de peixe está se instalando no município e obteve incentivos do município (terreno) para iniciar suas atividades. Observa-se, nesse sentido, a complementaridade entre as firmas, conforme teoria marshalliana.

Em relação ao recebimento de insumos e distribuição dos produtos acabados, identificou-se que o município possui localização estratégica quanto ao seu posicionamento geográfico e a disponibilidade de rodovias no que tange ao principal modal de transporte. Realizou-se um 
levantamento das informações no Departamento Nacional de Infraestrutura de Transportes (DNIT), identificando-se as principais rodovias para escoação da produção de Naviraí. A BR 163 é uma importante rota para escoamento da produção interligando o centro-oeste com o sul do Brasil e com a fronteira do Paraguai. A BR 487 e a MS 489 conectam o município com o norte do Paraná, região que possui diferentes rotas de escoação da produção para o mercado consumidor sul e sudeste, além de rotas para os portos de Paranaguá e Santos.

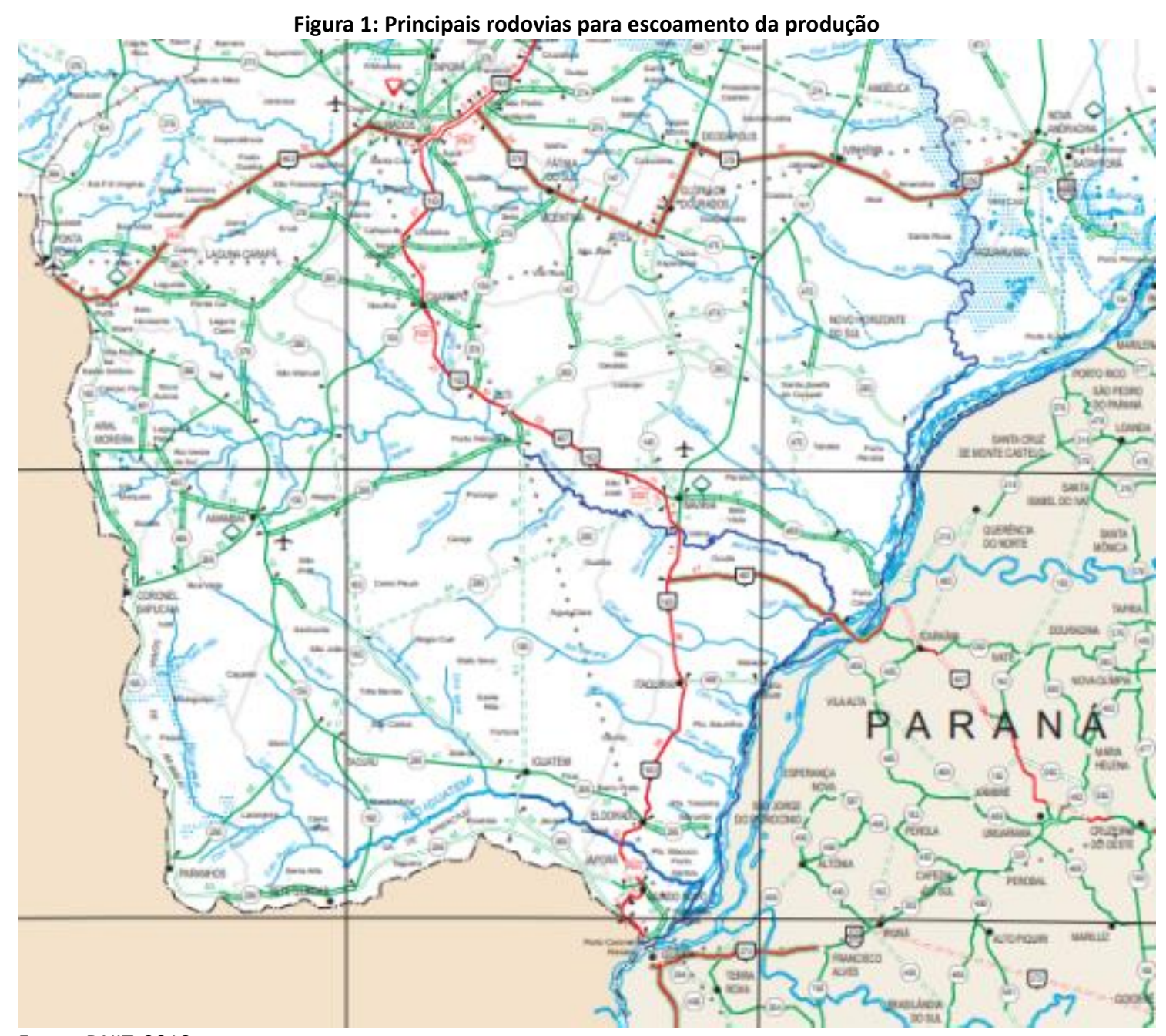

Fonte: DNIT, 2018.

Quanto ao mercado consumidor em potencial, determinou-se um raio de aproximadamente $300 \mathrm{~km}$ do município de Naviraí. Em seguida, realizou-se pesquisa sobre cada um dos municípios no IBGE Cidades, para levantar informações sobre o mercado consumidor regional. A soma da população dos 117 municípios pesquisados é de aproximadamente dois milhões de habitantes, com salário médio mensal dos trabalhadores de 02 salários mínimos.

Em termos de infraestrutura, quanto à água e energia, identificou-se que não há limitações que restrinjam as atividades industriais no município. Segundo FK "se for uma empresa que irá usar muita água, terá que ser feito poço artesiano e isso ela consegue através de uma licença 
do IMASUL e consegue fazer sem dificuldade, e a questão de energia também não há problemas". A despeito dessas observações, não foram investigadas as condições de acesso às tecnologias de informação e comunicação, que também podem impactar na decisão da localização de uma firma.

Conforme os fundamentos teóricos apresentados, outro fator que impacta fortemente na decisão locacional é a disponibilidade de mão de obra qualificada. Neste quesito, verificou-se que o município possui cursos de ensino superior importantes para a indústria agropecuária e de alimentos. O IFMS implantou em 2018 o curso de Agronomia neste município, enquanto a UEMS oferece os cursos de Engenharia de Alimentos, com previsão de formação da primeira turma para 2019 e possui turmas concluintes do curso superior de tecnologia em Alimentos. A UFMS implantou no primeiro semestre de 2017, o Curso de Administração no Câmpus de Naviraí. Outras universidades oferecem formação superior em diferentes áreas por meio da educação à distância. Nos últimos anos, o acesso ao ensino superior melhorou, fazendo com que o percentual de pessoas com 25 anos ou mais com superior completo de Naviraí (9,67\%) se aproximasse da taxa brasileira (11,27\%) (IBGE, 2010). Quanto ao ensino médio e fundamental, as diferenças são mais significativas comparativamente ao país. Por exemplo, a porcentagem de pessoas com 25 anos ou mais com médio completo em Naviraí é 27,99\%, superior à média da microrregião (20,93\%), mas inferior ao indicador nacional (35,83\%) (IBGE, 2010). Esses indicadores apontam que a cidade se destaca quanto à educação formal entre os municípios da microrregião, porém, quando comparado a outras regiões brasileiras, a educação ainda é um ponto negativo para o município.

Apesar dos baixos indicadores de educação formal, FK destaca que o município de Naviraí possui todas as instituições do sistema S, "nós temos todas as condições de receber empresas, porque aqui em Naviraí nós temos os cinco S (Senai, Sebrae, Senac, Sesi e Sesc), temos duas ou três universidades particulares, universidade federal (UFMS), instituto federal (IFMS) e vários cursos bons. Supondo que venha uma fabrica de jeans, teremos como dar cursos para capacitação. Temos capacidade de dar cursos para qualquer tipo de mão de obra. [...] Não é um fator que os empresários veem dificuldade".

$\mathrm{Na}$ perspectiva da entrevistada responsável pelo Centro de Atendimento ao Trabalhador (CIAT), principal agência para recrutamento de candidatos do município, em razão de a região ser voltada ao agronegócio, "não há muita qualificação porque nós não temos oferta de mão de obra para indústrias". A principal dificuldade para preenchimento de vagas na cidade ocorre em vagas específicas, por exemplo, mecânico industrial, EF cita. Em relação às especificidades de mão de obra para a indústria de alimentos, EF aponta a necessidade de a empresa firmar parcerias para a oferta de cursos em áreas específicas.

A entrevistada também menciona a importância do sistema $S$ para a qualificação profissional dos trabalhadores do município, mas menciona também a importância do interesse do jovem pelo mercado de trabalho. Segundo ela, é preciso "mostrar interesse em trabalhar, convencer do que quer e fazer uma carreira na empresa, não mudar todo mês pela oferta de outro lugar ser melhor". Cabe ressaltar que na percepção da entrevistada, a empresa é responsável pela qualificação do trabalhador para o cargo, "a dificuldade do empregador é de achar o candidato 
ideal e de encontrar a vontade, pois se ele tiver vontade de trabalhar, a parte da qualificação a empresa vai formar".

Quanto ao custo de mão de obra, realizou-se uma pesquisa das médias salariais no estado de Mato Grosso do Sul, consultando o ranking disponível na página do IBGE Cidades. Identificouse que o salário médio mensal em Naviraí é de 2,2 salários mínimos, enquanto em Dourados têm-se em média 2,6 salários mínimos mensais. Na capital do estado, Campo Grande, esse valor é 3,6 e em Três Lagoas, que se constitui como um polo industrial no estado, a média salarial é de 2,8 salários mínimos mensais. No ranking, Naviraí ocupa a $26^{\circ}$ posição, em ordem decrescente, no estado. Com isso, concluiu-se que o custo da mão de obra na cidade é mais baixo quando comparado a outras cidades do estado, constituindo-se como um fator que favorece a instalação de indústrias (IBGE Cidades, 2018).

A pesquisa também levantou os fatores institucionais, relacionados ao apoio do poder público visando à instalação de indústrias no município. Em termos de incentivos municipais, FK destaca que "o que temos de incentivo no município é o ISS de no máximo três anos, IPTU isento até cinco anos, terrenos que recebem em comodato inicialmente e após cumprimento do contrato de dez a quinze anos com geração de emprego e ICMS, pode adquirir o direito à propriedade". Os benefícios são solicitados pelas empresas, por meio de carta-consulta, com o registro das atividades, investimentos, empregos gerados e documentações legais, são analisados e votados pelo Conselho Municipal de Desenvolvimento Econômico, e, posteriormente, analisados e votados pelo poder legislativo.

Em relação aos incentivos estaduais, o governo de Mato Grosso Sul possui uma política agressiva visando ao desenvolvimento industrial do estado. De acordo com FK, se o estado de MS não possuir um tipo de indústria, pode-se conseguir isenção de até $90 \%$ de ICMS. Se a empresa comercializar o produto no estado, consegue isenção de 67\% do ICMS. Essa política fiscal do estado está prevista até o ano de 2032. Após esse período, segundo FK, está prevista uma política unificada para os estados, visando reduzir a guerra fiscal.

Outro fator importante, atrelado aos fatores institucionais, diz respeito à linha de crédito exclusiva para a região Centro-Oeste, incluindo o Mato Grosso do Sul, chamado Fundo Constitucional de Financiamento do Centro-Oeste (FCO), ofertado pelo Banco do Brasil, com prazos, limites e encargos financeiros diferenciados.

Além dos incentivos e benefícios oferecidos pelo poder público municipal e estadual, buscouse compreender se há, por parte do poder público, uma política de atração de indústrias específicas para o município. Neste quesito, identificou-se que o município busca a diversificação das atividades produtivas, embora FK destaque a importância de trabalhar com os recursos disponíveis no município. "A ideia também é atrair novos investimentos a Naviraí, em termos de indústrias, concessionárias, pois o nosso forte hoje é agroindústria. E temos muitas indústrias que já estão chegando" (FK).

Segundo ele, o governo municipal tem buscado empresas que trabalham com fabricação de bolas de futebol, confecção e uma olaria. FK destaca também que está se instalando no município uma empresa prestadora de serviço de manutenção para máquinas e equipamentos, que tem como foco a cana-de-açúcar. 
Especificamente, em relação às indústrias de alimentos, FK destaca que em outras localidades, como por exemplo, em Dourados, algumas indústrias produzem alimentos com matériasprimas vindas de outras localidades, citando o caso de uma indústria de massas. Uma das suposições iniciais do estudo estava relacionada à capacidade de produção de alimentos lácteos. Entretanto, conforme se identificou na entrevista com FK e nos dados obtidos por meio de pesquisa documental, não há produção de leite suficiente para instalação de laticínios em Naviraí, conforme se observa num trecho da entrevista: "hoje não temos uma produção de leite maior que $10.000 \mathrm{l} /$ dia com 100 produtores, e isso não comporta uma indústria de laticínios. Por isso, precisamos melhorar a genética do rebanho leiteiro, que é um trabalho de médio a longo prazo. Inclusive temos um projeto chamado leite com genética, que tem como objetivo melhorar a raça e o alimento do rebanho leiteiro para que ele produza mais e o produtor aumente a quantidade de leite fornecida. Assim conseguiremos trazer laticínios" (FK). Observa-se, portanto, que a diversificação dos alimentos produzidos no município carece de planejamento de curto, médio e longo prazo. A seguir são apresentadas as conclusões do estudo realizado.

\section{CONCLUSÕES}

Em síntese, pode-se dizer que a região não tem uma produção de alimentos diversificada, porém, possui fatores que podem favorecer a instalação de indústrias alimentícias, tais como localização estratégica, boa infraestrutura para transporte rodoviário, mão de obra pouco especializada de baixo custo baixo disponível e aumento do número de profissionais especializados, presença de instituições para qualificar os trabalhadores, boas condições em relação à infraestrutura de água e energia, incentivos fiscais, tributários e financeiros. Assim, conclui-se que a maioria dos fatores locacionais investigados favorecem a instalação de indústrias de alimentos no município.

Não se tinha a pretensão de esgotar todos os fatores locacionais neste estudo. Deste modo, recomenda-se que futuros estudos busquem analisar fatores como a presença de empresas especializadas em transporte terceirizado, eficiência do governo, infraestrutura em termos de sistemas de comunicação, os elementos intangíveis que são importantes para definir a qualidade de vida de uma população, como a presença de escolas, serviços de saúde, lazer, entre outros. Além disso, é possível aprofundar os estudos sobre os fatores locacionais por meio de novas fontes de evidência, realizando entrevistas com responsáveis pela gestão de pessoas das indústrias instaladas, com empresários do setor alimentício da região, entre outros.

Considerando as proposições da teoria marshalliana acerca da complementaridade entre as indústrias, considera-se que é importante investigar o potencial para o surgimento de indústrias subsidiárias próximas e serviços especializados, como por exemplo, uma indústria de embalagens. 


\section{REFERÊNCIAS BIBLIOGRÁFICAS}

ALMEIDA, Regis Rodrigues. Fatores locacionais da indústria. Mundo Educação. Disponível em: <http://mundoeducacao.bol.uol.com.br/geografia/fatores-locacionais-industria.htm>. Acesso em: 20 out. 2017

AMARAL FILHO, J. do. A endogeneização no desenvolvimento local e regional. Planejamento e Políticas PúblicasPPP, IPEA, Brasília, n. 23, 2001.

ANDRADE, B. A.. Distribuição Espacial Da Indústria Têxtil E De Confecção Em Pernambuco: Qual A Influência Dos Fatores Locacionais? Universidade Federal de Pernambuco: Programa de Pós-Graduação em Economia (PPGECON/CAA), 2016. Dissertação.

BAUER, M. W. Análise de conteúdo clássica: uma revisão. In: Bauer, M. W.; Gaskell, G. Pesquisa qualitativa com texto, imagem e som: um manual prático. 3a ed. Petrópolis (RJ): Vozes; 2002. p.189-217.

BETARELLI JUNIOR, A.; SIMÕES, R. F. A dinâmica setorial e os determinantes locacionais das microrregiões paulistas. Belo Horizonte: UFMG/CEDEPLAR, 2011.2 Disponível em: http://www.cedeplar.ufmg.br/pesquisas/td/TD\%20418.pdf (acesso em 18.05.17).

BRENE, P. R. A. et al.. Fatores Locacionais como Determinantes do Perfil Empresarial: uma proposta metodológica. Revista Brasileira de Gestão e Desenvolvimento Regional-G\&DR. v. 10, n. 2, p. 99-123, maio/ago. 2014.

CONFEDERAÇÃO NACIONAL DA INDÚSTRIA - CNI. Perfil da indústria. Disponível em: http://perfildaindustria. portaldaindustria.com.br/ranking?cat=10\&id=1756 (acesso em 15/07/2018).

DEPARTAMENTO NACIONAL DE TRÂNSITO - DNIT. Disponível em: Disponível em: http://www.dnit.gov.br/download/mapas-multimodais/mapas-multimodais/ms.pdf (acesso em 25/01/2018).

DINIZ, Clélio Campolina. Dinâmica regional e ordenamento do território brasileiro: desafios e oportunidades. Revista Catarinense de Economia, v. 1, n. 1, Florianópolis/SC, 2017.

DONDA JÚNIOR, Alberto. Fatores Influentes no Processo de Escolha da Localização Agroindustrial no Paraná: Estudo de Caso de uma Agroindústria de Aves. Florianópolis, UFSC, Programa de Pós-Graduação em Engenharia de Produção, 2002. Dissertação.

FERREIRA, B. M. O. B et al.. Considerações sobre a formação industrial de Mato Grosso do Sul. In: Anais do I Encontro Internacional de Gestão, Desenvolvimento e Inovação (I EIGEDIN). 12 a 14 de setembro de 2018. Naviraí/MS. Disponível em: http://seer.ufms.br/index.php/EIGEDIN/article/view/4315/3882 (acesso em 25 de dezembro de 2017).

FIUZA, S. N. et al. Localização industrial na Região Norte Fluminense: uma análise em termos de oferta e demanda por fatores locacionais. Revista Brasileira de Desenvolvimento Regional (G\&DR), v. 8, n. 3, p. 198-238, setdez/2012, Taubaté, SP, Brasil.

FONTANILLAS, C. N. et al. Estudo de critérios locacionais com vistas ao estabelecimento de vantagem competitiva. Sustainable Business Internacional Journal. ํ76, março de 2018. https://doi.org/10.22409/sbijounal2018.i76

FRIZONI, MATHEUS DE MORAES. 0 que é logística? Administradores. Disponível em: <http://www.administradores.com.br/artigos/marketing/o-que-e-logistica/48189/>. Acesso em: 23 out. 2017

IMASUL. Legislação Ambiental. Disponível em: < http://www.imasul.ms.gov.br/legislacao-ambiental/>. Acesso em: 16 nov. 2017

INSTITUTO BRASILEIRO DE GEOGRAFIA E ESTATÍSTICA - IBGE. IBGE Cidades - Ranking Estatístico. Disponível em: https://cidades.ibge.gov.br/ (acesso em 25/01/18).

LUCIANE, Baruffi; CERETTA, Gilberto Francisco; ROCHA, Adilson Carlos. Potencial de desenvolvimento: um estudo do apl de alumínio na região sudoeste do Paraná. Revista Estudos do CEPE, n. 39, p.157-180, jan./jun. 2014.

MARSHALL, Alfred. Princípios de economia: tratado introdutório. São Paulo: Abril Cultural, 1982. 
PEREIRA, J. A. et al.. Desenvolvimento local e regional: características da microrregião de Iguatemi do Estado de Mato Grosso do Sul. In: II SimPPA - Simpósio do Programa de Pós-Graduação em Administração, 2., 2017, Maringá. Anais... Maringá, SimPPA, 2017.

PRODANOV, Cleber Cristiano; FREITAS, Ernani Cesar de. Metodologia do Trabalho Científico: Métodos e Técnicas da Pesquisa e do Trabalho Acadêmico. Rio Grande do Sul: Feevale, 2013.

RAMOS, Rui António Rodrigues. Localização Industrial: um modelo espacial para o noroeste de Portugal. Tese de Doutorado. Universidade do Minho. Escola de Engenharia. Portugal, 2000. Disponível em: http://hdl.handle.net/1822/184 (acesso em 15/02/2018).

ROCHA, R. de M.; BEZERRA, F. M.; MESQUITA, C. S.. Decisão locacional das firmas: um exame empírico dos fatores de aglomeração da indústria de transformação brasileira. In: XIII Encontro Regional de Economia - ANPEC, Porto Alegre/RS, Anais...Porto Alegre, $2010 . \quad$ Disponível em: http://www.anpec.org.br/encontro2010/inscricao/arquivos/477-d891a36bebfe4072565fae93ac1ce5bc.pdf . Acesso em: 10 de maio de 2017.

ROMERO, Suelene Mascarini de Souza. Inovação e Território: Analise dos fatores locacionais que afetam a inovação do Brasil. Tese de doutorado. Escola Politécnica. Universidade de São Paulo, 2017, 192 p.

SECRETARIA DE ESTADO DE MEIO AMBIENTE E DESENVOLVIMENTO ECONÔMICO - SEMADE. Perfil estatístico de Mato Grosso do Sul - 2015.

SILVEIRA, Denise Tolfo; CÓRDOVA, Fernanda Peixoto. Métodos de pesquisa. Disponível em: <http://www.ufrgs.br/cursopgdr/downloadsSerie/derad005.pdf>. Acesso em: 15 dez 2017.

SOUZA, L. A.; MUNIZ, A. L. P.. Os Fatores Determinantes Da Localização Das Indústrias Goianas. Revista CEPPG, n. 23, V. 2010, 20 p. 20161/175. http://www.portalcatalao.com/painel_clientes/cesuc/painel/arquivos/upload/temp/b54a68655425329b796698be 783183f0.pdf (acesso em 25.05.17).

STAMM, C. ET AL. A população urbana e a difusão das cidades de porte médio no Brasil. INTERAÇõES, Campo Grande, v. 14, n. 2, p. 251-265, jul./dez. 2013.

STEIN, Natália Branco. A distribuição espacial da indústria gaúcha: uma analise dos fatores de localização e das políticas publicas de incentivo à indústria. Dissertação. Programa de pós-graduação em planejamento urbano e regional. Universidade Federal do Rio Grande do Sul. 2015. 175p. 